\title{
Healthcare and Leadership Competencies, Training Methods, and Venues
}

\author{
Bernardo Ramirez \\ University of Central Florida
}

\author{
Daniel J. West, Jr. \\ University of Scranton
}

\author{
Cherie Lynn Ramirez \\ Simmons University
}

\begin{abstract}
Healthcare systems and health organizations are amongst the most complex and ever-changing human and social enterprises. All countries in the world are involved in various phases of health reforms to expand access, improve quality, and/or control costs. The choice of which structures to use for public and private healthcare initiatives, including Public-Private Partnerships (PPPS), is influenced by economic factors. A high level of professionalization is needed throughout the different levels of these multidisciplinary establishments to ensure effective management. In some healthcare delivery models, increased attention has been given to the significance of quality assurance in higher education and professional leadership development of clinician and healthcare managers' teams. The International Hospital Federation (IHF) has been involved in efforts to characterize healthcare management competencies and create tools to ensure that healthcare managers and organizations can be more aware of their strengths and aspects needing improvement. We provide an overview of the IHF competencies as well as what training methods and venues are available to help promote professional development of healthcare managers.
\end{abstract}

Keywords: competencies, professionalization, healthcare management development, training managers, training venues

\section{INTRODUCTION}

With a very sharp focus on improving population health, physicians and hospitals are developing health systems that vertically align healthcare systems with the continuum of care. The International Hospital Federation (IHF) is a not-for-profit non-governmental organization based in Geneva, Switzerland working to create healthy communities around the world and to ensure that hospitals are efficient and well-managed so that they can provide high quality, accessible, patient-centered care. The IHF sponsors the "World Hospital Congress" that is hosted by national hospital associations in different countries every year, hosts an online interactive exchange platform with Special Interests Groups (SIGs), and publishes and disseminates reports (IHF). The IHF developed a Competency Directory composed of domains and subdomains (IHF, 2020). The Global Consortium for Healthcare Management Professionalism has focused on the international health community to recognize that healthcare changes and improvements can be made. 
The consortium also asked for adoption of the "Global Healthcare Management Competency Directory" to facilitate development of healthcare management frameworks and programs for use by academic institutions and relevant licensing and accrediting organizations (IHF, 2020). The Global Healthcare Management Competency Directory can be used in healthcare management development programs at the undergraduate, post-graduate, and ongoing professional continuing education levels. The IHF recognizes healthcare management as a profession and competency development of managers and leaders as an imperative. The IHF competency model has five domains as follows:

- Leadership: The ability to inspire individual and organizational excellence, create a shared vision and successfully manage change to attain an organization's strategic ends and successful performance. Leadership intersects with the other four domains.

- Communication and Relationship Management: The ability to communicate clearly and concisely with internal and external customers, establish and maintain relationships, and facilitate constructive interactions with individuals and groups.

- Professional and Social Responsibility: The ability to align personal and organizational conduct with ethical and professional standards that include a responsibility to the patient and community, a service orientation, and a commitment to lifelong learning and improvement.

- Health and the Healthcare Environment: The understanding of the healthcare system and the environment in which healthcare managers and providers function.

- Business: The ability to apply business principles, including systems thinking, to the healthcare environment.

Healthcare managers and leaders are encouraged to demonstrate competency in all five domain areas. The IHF encourages involvement by governments, academia, professional groups and associations, international organizations and agencies, consulting firms, employers, and individuals.

The SIG developed in the area of health management has two main goals: (1) to provide the professionalization of health management discipline, and (2) to build global capacity in leadership and management of health systems (IHF). The SIG is focused on advancing healthcare management system improvements to achieve value-added patient care, stimulate the collaboration with academic centers and accrediting bodies, promote and support emerging hospital and healthcare management national associations, and to strengthen the healthcare management profession around the globe.

\section{Education, Training, and Professional Development}

The most important takeaway regarding leadership competencies in healthcare is that universities and professional organizations need to consider various types of education and training to address competencies and competency development during the entire continuum of professional development and career progression of healthcare managers (Figure 1). Addressing global health and population health issues requires an informed and educated leadership team across the continuum of care and within all healthcare organizations.

The continuum for management development and performance considers, as one of its components, formal education and research, where theories and principles are learned in the context of scientific disciplines through academic education and research. Then the continuum progresses into areas of specialization, continuing education, and retraining that mostly take place in professional academies or training institutes typically linked to operating healthcare organizations. After that, we have the various levels and programs that are institutional and related to human resources and on-the-job (OTJ) training departments. These opportunities are intrinsically coordinated with healthcare facilities of all types, including hospitals. Finally, team development under units and departments focuses on performance improvement by following guidelines and job descriptions through continued performance quality assessment, mentoring, and development of individual competencies. 
FIGURE 1

MANAGEMENT DEVELOPMENT AND PERFORMANCE CONTINUUM

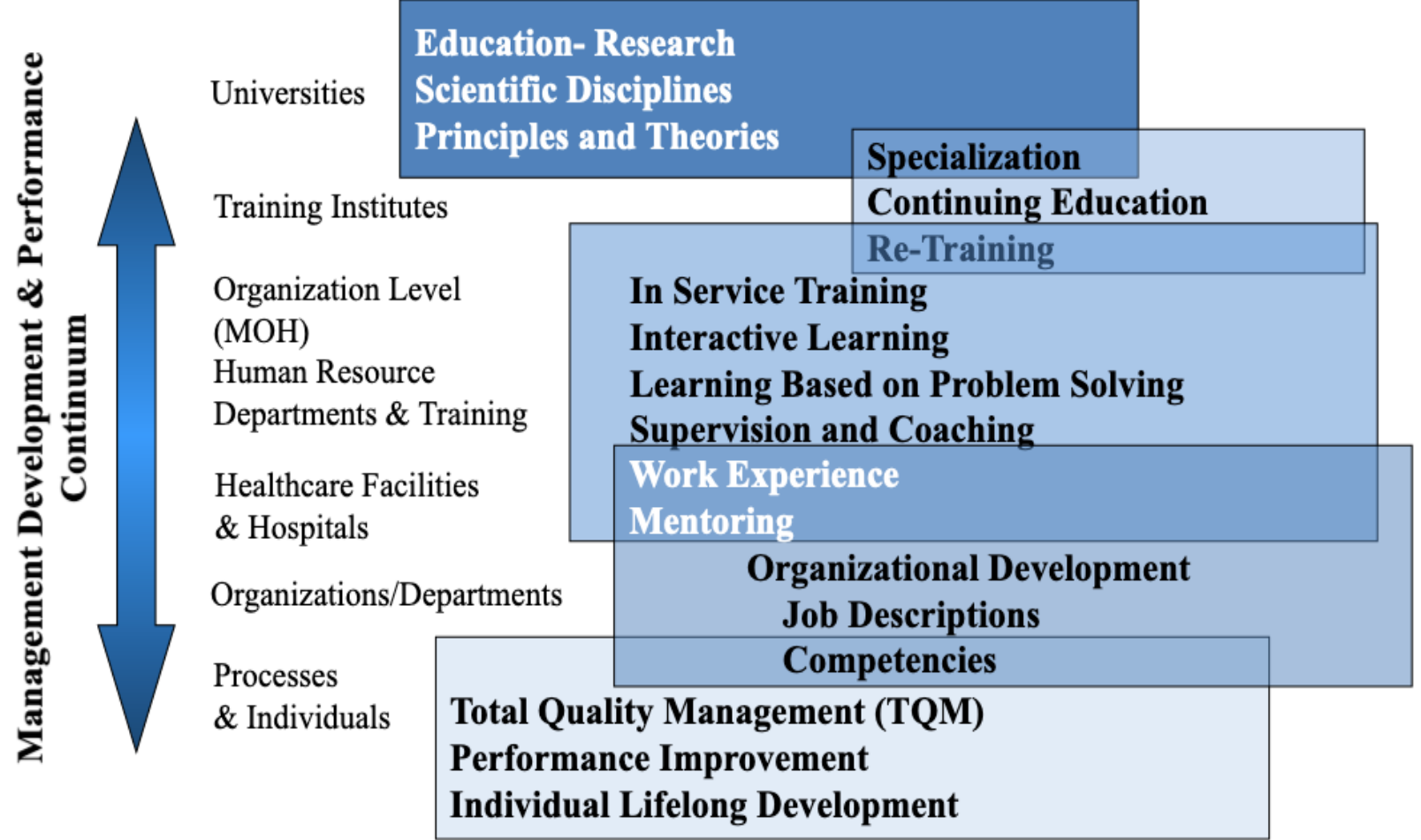

Competencies are supported by a body of knowledge for that particular discipline or area of practice and performance, in this case leadership and healthcare management. Then we need to consider that each competency reflects a balanced combination of knowledge, skills, and attitudes. In order to exhibit the required level of performance for a managerial practice, we have to understand and know what it is that we need to do (knowledge), then we have to be able to do it (skills), and finally we need to want to do it and have a given level of comfort and willingness to act (attitudes). The depth and amount of each one of these elements might vary according to the complexity of the task and our level of competency, but always requires an appropriate combination of these three elements.

Finally, as indicated in Figure 2, the way we increase and develop our competencies is by levels of performance. In a typical organization or throughout career advancement, there is a progression from entry level to mid-level to advanced or senior level of development and competency performance. Appropriate institutional support and mentoring are key ingredients to succeed in performing well and making progress toward new goals. 
FIGURE 2

CASCADING COMPETENCY MODEL
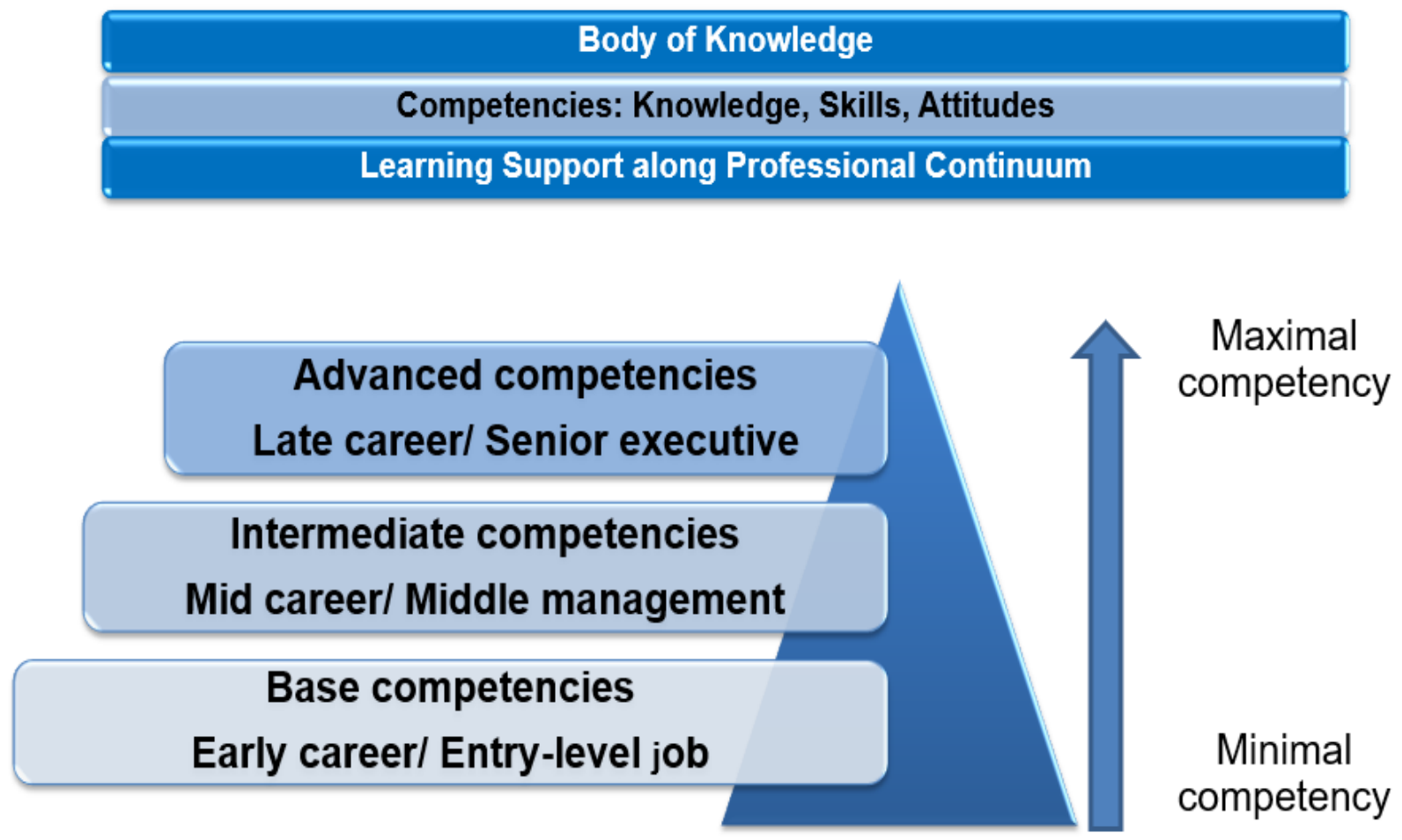

\section{Development and Educational Venues}

Current research on diverse types of public and private healthcare organizations in several parts of the world and involving university-based models strongly suggests that using different venues of education will be required to develop competencies at different levels within organizations and across healthcare systems (Giles 2016; Herd, et al., 2016; Begun, et al., 2018; Broom \& Gentry, 2018; Garman, 2018; Ramirez, B., et al., 2018; Ramirez, C.L., et al., 2018; Szydlowski, et al. 2018).

As indicated in Figure 3, various types of educational and training strategies and activities are required to facilitate the development of competencies. Some of them, like conferences, could be appropriate for developing knowledge, understanding and analyzing theories and principles, and differentiating and contrasting concepts and elements of an action plan. In order to develop skills, individuals need to be exposed to sufficient - often multiple - opportunities to apply that knowledge, practice taking action, and getting feedback, for example, through OJT, workshops, case studies, guided practices, internships, or field work experiences. Probably the most difficult competencies to achieve require the self-confidence and willingness to act and be self-propelled to intervene, make decisions, and execute. Often, participating in observations, having role models, shadowing, and fellowships will be essential to motivate and inspire individuals to perform with confidence, be able to ask questions, and ideally also receive feedback. Tutoring and mentoring is a key ingredient to internalize and achieve a high level of competence.

Varied levels of professional development will also require different types of education and training strategies to facilitate progressive advancement and mastery of competencies (Fick, et al., 2018). 


\section{FIGURE 3 \\ LEVELS OF PROFESSIONAL DEVELOPMENT AND TYPES OF \\ EDUCATION AND TRAINING}

\section{Entry Level}

- Self Assessment

- OJT

- Observation

- Tutoring

- Grand Rounds

- Case Studies

- Formal Education

- Community Service
Mid Level

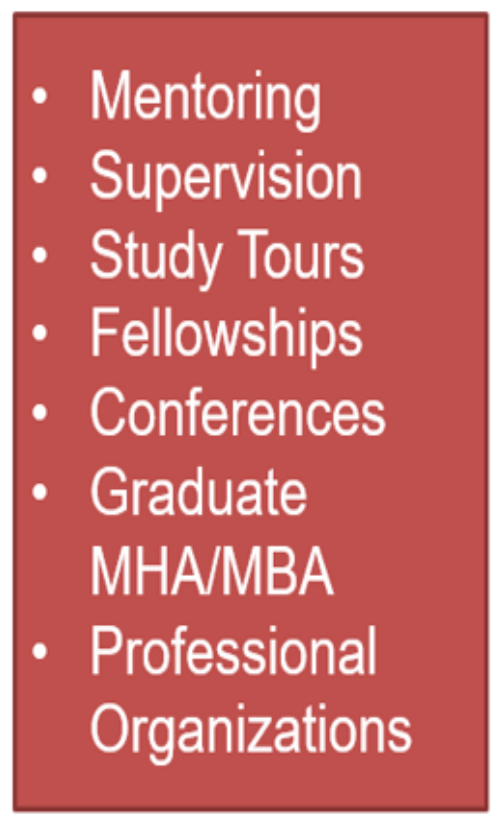

Advanced Level

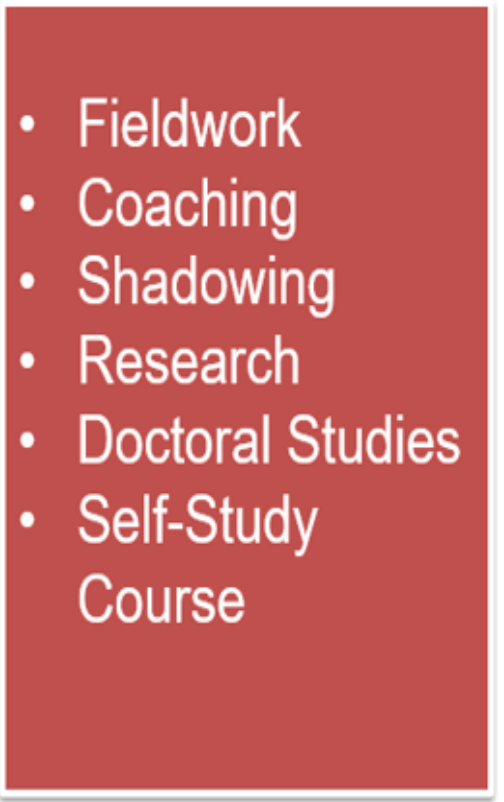

Below are some typical venues for educational offerings that may be relevant to consider for future interventions to promote competency development of managers:

- Higher Education Classrooms: There are many venues and technologies that the health professions have used over the last several decades. Traditional forms of degreed education (such as face-to-face classroom experiences) continue to dominate young adult and early college-level education. However, more post-graduate education is being offered in online formats. Competency-based education continues to shape the undergraduate and graduate level professional degrees with employers demanding appropriate levels of knowledge, skills, and competencies upon degree completion. Traditional programs of classroom education often offer applied residency or internships to further develop practitioner-based experiences.

- Professional Associations: Professional organizations such as hospital associations, health professions associations (physicians, nurses, etc.), and colleges of healthcare executives provide continuing education for clinicians and leaders to maintain credentials and currency with the changing body of knowledge, skills, and competencies needed. This venue provides both in-person and online educational opportunities specific to trends in the given industry. This venue may be best suited for individuals currently serving as executives.

- Educational Offerings by Public and Private Entities: Educational sessions coordinated through international organizations such as the IHF, the World Bank, the World Health Organization, the United States Agency for International Development (USAID), and the European Commission, to name a few, provide developmental training and learning for vested stakeholders. Additionally, webinars, blogs, and other internet-supported dissemination and learning modalities continue to serve as vehicles for education and training. These organizations offer continuous advanced and state of the art learning resources and support activities to address current skills and trends in the given discipline. 
- On-Site Training: When larger numbers of individuals are in need of training, on-site organizational training sessions can provide the best value to support greater access with lower costs. This training can take place face-to-face or online. By utilizing internal education staff members or relying on outside expertise to offer training, on-site programming can reach the largest number of employees at a lower unit cost. The venue for training and education is influenced by the context of the case at hand. This venue may be most suitable when large numbers of employees need to develop common competencies around communication skills, relationship management, and other important topics that impact organizational culture.

\section{Future Directions for Competency Development}

The development of competency models is a continuously evolving activity that requires the collaboration of practicing professionals, healthcare organizations, and academic and educational entities. For example, the current competency model used by many professional associations including the IHF is the leadership competency inventory described in this paper, which is under review to be further refined. The National Center for Healthcare Leadership has published an updated career-spanning competency model for health sector leaders that revised and revalidated the model, organizing it around four competency action domains (Boundary Spanning, Transformation, Execution, and Relations) and three enabling competency domains (Health System Awareness \& Business Literacy, Self-Awareness \& SelfDevelopment, and Values [Professional, Organizational, and Personal]) (NCHL, 2018).

At the same time, the IHF Healthcare Management SIG group continues to support research initiatives to further develop the use and impact of competencies in the professionalization of healthcare management and the improvement of management practices with different strategies such as: (1) supporting projects that study the impact of the competencies on the improvement of healthcare management practices; and (2) developing and collecting training references and materials for the development of all the competencies included in the IHF inventory so that after practitioners take the online assessment and discover which competencies they need to improve, they can access those materials in an IHF database (West, et al., 2018; Hernandez, et al., 2018). Ideally, efforts will be made to co-evolve the IHF competencies along with standardization policies, strategic priorities, quality-assurance standards, and accreditation criteria of both educational and healthcare institutions. These actions will support the continued recognition and professionalization of healthcare management as a cornerstone to improve clinical and managerial best practices and promote better quality and performance of healthcare organizations worldwide.

\section{REFERENCES}

Begun, J.W., Butler, P.W., \& Stefl, M.E. (2018). Competencies to What End? Affirming the Purpose of Healthcare Management. The Journal of Health Administration Education, 35(2), 133-155.

Broom, K., \& Gentry, D. (2018). The Past, Present and Future; Our Journey through Competency-Based Education. The Journal of Health Administration Education, 35(2), 123-132.

Fick, J.W., Dishman, L., Adler, K., \& Williams, L. (2018). Exploring Hospital CEOs' Perceptions of Health Administration Graduates' Leadership Competencies. The Journal of Health Administration Education, 35(2), 229-267.

Garman, A.N. (2018). Competency-Based Education in Healthcare Management: Current State \& Future Directions. The Journal of Health Administration Education, 35(2), 119-122.

Herd, A., Adams-Pope, B.L., Bowers, A., \& Sims, B. (2016). Finding What Works: Leadership Competencies for the Changing Healthcare Environment. Journal of Leadership Education, 15(4), 217-233.

Hernandez, R., O'Connor, S.J., \& Meese, K.A. (2018). Global Efforts to Professionalize the Healthcare Management Workforce: The Role of Competencies. Journal of Leadership Education, 15(4), $158-174$.

IHF-International Hospital Federation. (2020). Leadership Competencies for Health Services Managers. Retrieved July 4, 2021, from https://www.ihf- 
fih.org/resources/pdf/Leadership_Competencies_for_Healthcare_Services_Managers.pdf?202003-31

IHF-International Hospital Federation. (n.d.). Healthcare Management Special Interest Group (SIG). Retrieved from https:/www.ihf-fih.org/activities/special-interest-groups/healthcare-management/

NCHL-National Center for Healthcare Leadership. (2018). Health Leadership Competency Model 3.0. Retrieved from https://www.nchl.org/research/\#NCHL_Health_Leadership_Competency_Model_30

Ramirez, B., West, D., \& Wan, T. (2018). Leadership and Management Competencies to Advance ValueBased Healthcare. Presented at the 42nd World Hospital Congress of the International Hospital Federation in Brisbane Australia, October 10.

Ramirez, C.L., Ramirez, B., Hurtado, A., West, D., Costello, M., Szydlowski, S., \& Miller, W. (2018). Public-Private Partnerships (PPPs) in Health Care: Gauging Leadership Competencies of Hospital Managers. Presented at the $18^{\text {th }}$ Annual Conference of the European Academy of Management. Reykjavik, Iceland, June 21.

Szydlowski, S., Ramirez, B., Costello, M., West, D., Ramirez, C.L., Hurtado Belendez, A., \& Miller, W. (2018). Using International Hospital Federation Leadership Competencies for Educating Participants in Healthcare Public-Private Partnerships. The Journal of International Management Studies, 13(2), 19-26.

West, D., \& Ramirez, B. (2018). A Competency-Based Approach to Enhance Healthcare Management: How to Make a Best Use of It. Presented at the $42^{\text {nd }}$ World Hospital Congress of the International Hospital Federation in Brisbane Australia, October 11.

West, D., Ramirez, B., Filerman, G., Stanowski, A., Vasadze, O., Malik, A.M., . . Kromery, V. (2019). Global Accreditation Strategies in Health Management Education. Frontiers in Public Health, $7(12), 1-6$. 